Karla Victoria Nable-Llanes, MD

Rodante A. Roldan, MD

Department of Otorhinolaryngology

Head and Neck Surgery

Rizal Medical Center
Correspondence: Dr. Rodante A. Roldan Department of Otorhinolaryngology

Head and Neck Surgery

Rizal Medical Center, Pasig Blvd., Pasig City 1609

Philippines

Phone: (632) 88658400 local 207

Email: raroldanmd@gmail.com

The authors declared that this represents original materia that is not being considered for publication or has not been published or accepted for publication elsewhere in full or in part, in print or electronic media; that the requirements for authorship have been met by all the authors, and that each author believes that the manuscript represents honest work.

Disclosures: The authors signed a disclosure that there are no financial or other (including personal) relationships, intellectual passion, political or religious beliefs, and institutional affiliations that might lead to a conflict of interest.

Presented at the Philippine Society of Otolaryngology-Head and Neck Surgery 1st Virtual Descriptive Research Contest (1st Place), October 21, 2020

\section{Predominant Endotype of Nasal Polyps in a Sample of Filipinos Following Endoscopic Sinus Surgery for Chronic Rhinosinusitis with Nasal Polyposis}

\begin{abstract}
Objective: To determine the prevalence of eosinophilic and non-eosinophilic nasal polyps in Filipino patients with chronic rhinosinusitis with nasal polyposis (CRSwNP) who underwent endoscopic sinus surgery.
\end{abstract}

Methods:

\section{Design: Retrospective Chart Review \\ Setting: $\quad$ Tertiary Government Training Hospital}

Participants: A consecutive sample of adult patients who underwent endoscopic sinus surgery for chronic rhinosinusitis with nasal polyposis at the Rizal Medical Center from 2015-2019.

Results: Out of 66 patients who underwent endoscopic sinus surgery during the study period, $36(54.55 \%)$ had an eosinophilic endotype while $30(45.45 \%)$ had a non-eosinophilic endotype.

Conclusion: The slight predominance of eosinophilic nasal polyps found in our sample may suggest a contrasting trend compared to our Asian neighbors, who have a predominantly noneosinophilic endotype - Indonesia (90.47\%), Thailand (81.9\%), South Korea (66.7\%) and China (53.6\%). However, this predominance is still lower than the 78-88\% eosinophilia reported among Caucasians. Larger series may confirm these preliminary findings.

Keywords: chronic rhinosinusitis; paranasal sinuses; sinusitis; nasal polyps; eosinophilic polyps; noneosinophilic polyps; endotype

Chronic rhinosinusitis (CRS) is the symptomatic inflammation of the nose and paranasal sinuses of at least 12 weeks duration arising from complex inflammatory processes triggered by an array of exogenous agents. It is a common medical condition with a prevalence of $10.9 \%$ across different countries in Europe, ${ }^{2} 11.9 \%$ in the United States, ${ }^{3} 8 \%$ in China, and 8.6\% in South Korea. ${ }^{4}$ Clinically, CRS is generally divided into two broad categories-CRS with nasal polyposis (CRSwNP) and CRS without nasal polyposis (CRSsNP). Over the past decade, research has revealed unique cytokine and cellular inflammatory profiles in CRSwNP to further classify nasal polyps as those with a $\mathrm{TH} 2$ response that have an eosinophil cellular predominance, and those with a $\mathrm{TH} 1 / \mathrm{TH} 17$ response with a neutrophil (non-eosinophil) cellular predominance. ${ }^{5}$ The mechanism of inflammation in each individual which leads to the activation of different types of T-helper 
cells causing eosinophilic or non-eosinophilic patterns of inflammation is expressed as their endotype. ${ }^{6}$

The prevalent inflammatory profiles have been shown to vary across different countries with western countries mostly showing a TH2 predominance (France 88\%, Belgium 78\% ${ }^{8}$ ) and Asian countries showing a TH1/TH17 predominance (Indonesia 90.47\%, ${ }^{9}$ Thailand $81.9 \%,{ }^{10}$ South Korea $66.7 \%,{ }^{11}$ China $53.6 \%{ }^{12}$ ). The presence of mucosal eosinophilia is frequently associated with more severe disease and recurrence of nasal polyps after surgery. ${ }^{13}$ We could find no published data on the prevalent inflammatory profile for nasal polyps among Filipinos based on a search of HERDIN Plus, the ASEAN Citation Index, Global Index Medicus, or PubMed (MEDLINE, PMC).

Thus, the aim of this study is to determine the prevalence of eosinophilic and non-eosinophilic nasal polyps in Filipino patients with CRSwNP who underwent endoscopic sinus surgery in our hospital in order to determine the predominant inflammatory profile that may inform treatment, prognostication, and monitoring for response and recurrence post-treatment.

\section{METHODS}

With Institutional Review Board approval (2019-ORL-\#71-RP-1.II), this retrospective study consecutively reviewed the hospital records of all adult patients with chronic rhinosinusitis with nasal polyposis (CRSwNP) who underwent endoscopic sinus surgery over a five-year period from January 2015 to December 2019. The diagnosis of CRSwNP was based on patient history, clinical examination, nasal endoscopy, and computed tomography (CT) of the sinuses. Excluded were records of those with immunodeficiency or in an immunocompromised state, blood dyscrasias, auto-immune diseases or genetic disorders affecting mucociliary clearance (i.e. cystic fibrosis, primary ciliary dyskinesia), non-invasive fungal balls and invasive fungal disease, cocaine abuse, antrochoanal polyps, septal perforations, trauma to the facial skeleton (except for the mandible), neoplasia, nasal malignancies, aspirinexacerbated respiratory disease, or pregnancy.

Preoperative demographic data and medical histories were obtained from the medical records, including age, sex, history of prior sinus surgery, history of asthma and/or allergic rhinitis, history of other types of atopy such as food allergies and/or atopic dermatitis, as well as smoking history. Polyps were graded using the Lund-Mackay Score: ${ }^{14}$ grade 1, polyps in middle meatus only; grade 2, polyps beyond the middle meatus but not blocking the nose completely; grade 3, polyps completely obstructing the nose. All participants had been assessed for symptom severity prior to surgery using the Sino Nasal Outcome Test $\left(\right.$ SNOT-22) ${ }^{15}$ and underwent guideline-directed treatment including but not limited to intranasal corticosteroids, pre-operative oral steroids for 1 week and post-operative oral steroids for 1 week. The raw data acquired from the review of patient inpatient and outpatient charts was evaluated for measures of central tendencies and percentages.

Post-operative surgical pathology reports of nasal polyp specimens routinely contain eosinophil counts in our institution since 2015 and undergo the same processing according to hospital protocol. Nasal polyps of patients with CRSwNP removed during endoscopic sinus surgery were fixed immediately in 10\% formalin and sent for processing by the histopathology section. Histopathologic analysis was done through examination of the areas of densest cellular infiltrates, counting the number of eosinophils in the mucosa under high-power field (HPF, 400X). Counting was performed for 3 separate HPFs and the 3 counts were then averaged to calculate the average number of mucosal or polyp eosinophils per HPF. All specimens were examined microscopically by a board-certified pathologist unaware of the clinical data and the eosinophil count was routinely included in the final report. Post-operative histopathology reports were collected and reviewed to determine the endotype. In this study, the official surgical pathology reports were reviewed and nasal polyps were classified according to the system proposed by Kountakis et al.; eosinophilic nasal polyps are those that are histologically confirmed to have more than 5 eosinophils/HPF in the densest area of infiltration, while non-eosinophilic nasal polyps are those that are histologically-confirmed to have less than or equal to only 5 eosinophils/HPF in the densest area of infiltration. ${ }^{16}$

The raw data acquired from the review of inpatient and outpatient charts was collated using Microsoft Excel Version 14.7.7 (Microsoft Corporation, Redmond, WA, USA) and evaluated for measures of central tendencies and percentages.

\section{RESULTS}

A total of 79 patients underwent endoscopic sinus surgery in Rizal Medical Center from 2015-2019. Of these, eight (8) and two (2) patients were excluded due to antrochoanal polyps and malignancy, respectively. The histopathology results of three (3) patients could not be found, and these were further excluded.

A total of 66 complete patient records with surgical pathology reports were included in the final consecutive sample. The mean age was 42.73 (range 20-71 years old), with 53 (80.3\%) males and 13 (19.7\%) females. Thirty-three patients (50\%) were smokers or had a history of smoking, 10 (15.15\%) had a history of previous sinus surgery while 56 $(84.85 \%)$ underwent primary sinus surgery.

Out of the 66 patients, 36 (54.55\%) had an eosinophilic endotype while 30 patients (45.45\%) had a non-eosinophilic endotype. Of the 36 patients with eosinophilic endotype, 7 (19.44\%) and 15 (41.67\%) respectively had a history of asthma or other forms of atopy. Other 


\section{ORIGINAL ARTICLES}

forms of atopy present in the eosinophilic group were allergic rhinitis in $9(25 \%)$ and food and/or drug allergies in $6(16.67 \%)$. In contrast, none of the 30 patients with a non-eosinophilic endotype had a history of asthma while 7 (23.33\%) had a history of other forms of atopy. Other forms of atopy present in the non-eosinophilic group were allergic rhinitis in 4 (13.33\%) and food and/or drug allergies in $3(10 \%)$. (Figure 1)

The data revealed outliers, hence the mean was not used to report the results. The median of the pre-operative SNOT-22 score of the eosinophilic group was 50.5 (range 9-112, IQR 38.25), while the median of the non-eosinophilic group was 38 (range 7-103, IQR 30.25). Thirty percent (30\%) of the non-eosinophilic group had prior sinus surgery with an average interval between surgeries of 18.33 years (range 1-37). In the eosinophilic group, only 1 patient had prior sinus surgery with an interval of 9 years between surgeries. Conversely, $9(90 \%)$ of those who had prior sinus surgery were classified to have the non-eosinophilic endotype. The summary of nasal polyp grading is reported in Table 1.

\section{DISCUSSION}

The data revealed that the sample of patients with CRSwNP who underwent endoscopic sinus surgery in Rizal Medical Center between 2015-2019 had a prevalence of 54.55\% eosinophilic endotype, and $45.45 \%$ non-eosinophilic endotype. These findings are similar to the unpublished observations of Javierto et al. in this same institution which found a prevalence of $53 \%$ favoring eosinophilic endotype in Filipino nasal polyps from 2008-2012..$^{17}$ Notably, the predominance of this endotype differs from our Asian counterparts who reported predominance of the non-eosinophilic endotype.-12 In contrast, western countries are of the same endotype, however the prevalence of eosinophilic nasal polyps in Filipinos are far below their reported rates. ${ }^{7.8}$ This discrepancy may be due to differences in genetics, and/or be attributed to the differing parameters and cut-off values utilized in their respective studies.

The literature is rife with different cut-off values to determine mucosal eosinophilia, ranging from $>5 / \mathrm{hpf}$ to $>350 / \mathrm{hpf}^{7-12,18,19}$ We selected the cut-off value proposed by Kountakis et al., as their immunohistochemical studies for EG2, a marker for activated eosinophils, stained positive in all nasal polyp tissue specimens with more than 5 eosinophils/HPF, while those with 5 eosinophils or less did not stain positive for $E G 2 .^{16}$

Eosinophilic CRSwNP is also associated with decreased likelihood of surgical success and recurrence of disease within 5 years after surgical intervention with a positive predictive value of $87.5 \% .^{20}$ Studies correlate the eosinophilic endotype with more severe disease and a higher association with recurrence and need for revision sinus surgery. ${ }^{16}$ The opposite was observed in this study where $90 \%$ of the
Table 1. Distribution of nasal polyp grading for eosinophilic and non-eosinophilic groups

\begin{tabular}{|c|c|c|}
\hline $\begin{array}{c}\text { Polyp Grade } \\
\text { right, left }\end{array}$ & $\begin{array}{c}\text { Eosinophilic } \\
\mathbf{N}(\%)\end{array}$ & $\begin{array}{c}\text { Non-Eosinophilic } \\
\mathbf{N}(\%)\end{array}$ \\
\hline 3,3 & $8(22.22)$ & $9(30.00)$ \\
\hline 3,2 & $14(38.89)$ & $12(40.00)$ \\
\hline 2,2 & $11(30.56)$ & $5(16.67)$ \\
\hline 2,1 & $1(2.78)$ & $1(3.33)$ \\
\hline 2,0 & $1(2.78)$ & $3(10.00)$ \\
\hline 1,1 & $1(2.78)$ & $0(0.00)$ \\
\hline 3,1 & $0(0.00)$ & $0(0.00)$ \\
\hline Total & 36 & 30 \\
\hline
\end{tabular}

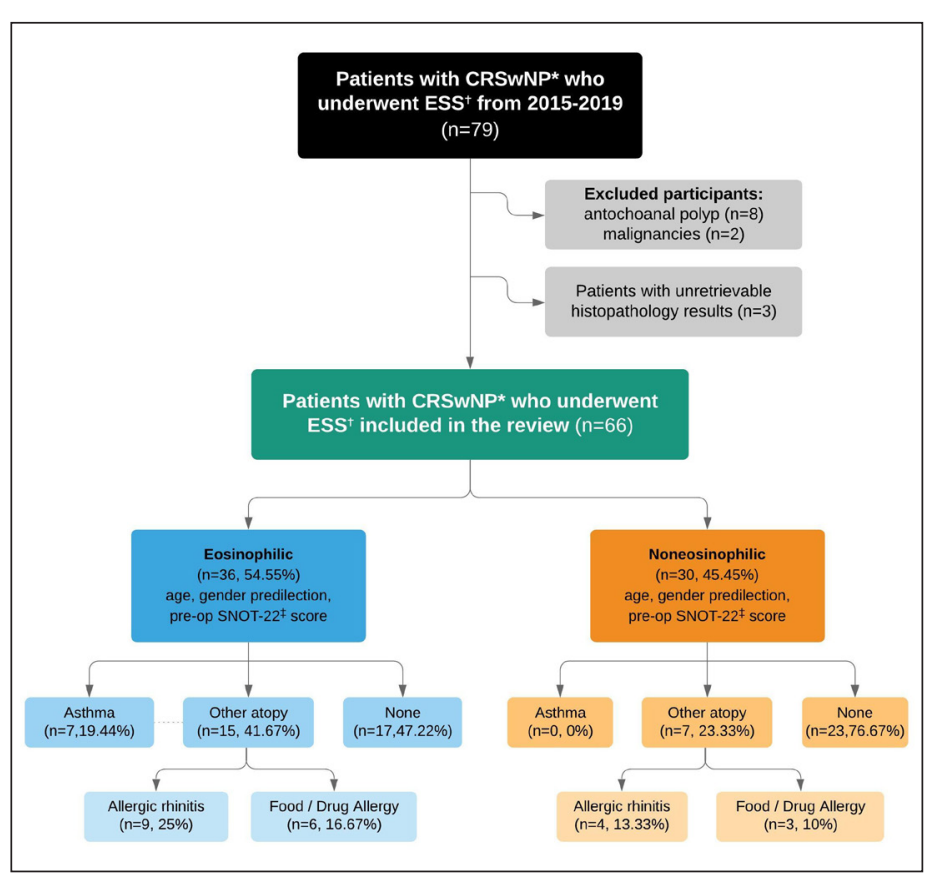

Figure 1. Endotype classification and history of asthma or other forms of atopy in each endotype Legend: *CRSwNP Chronic Rhinosinusitis with Nasal Polyposis; + ESS Endoscopic Sinus Surgery; $¥ S N O T-22$ Sinonasal Outcome Test-22

patients who had prior sinus surgery were classified under the noneosinophilic endotype. The retrospective nature of this study, precludes determining why this is so, but a possible explanation could be routine use of intranasal corticosteroids in CRSwNP patients which would benefit the eosinophilic group and control their symptoms, whereas the non-eosinophilic group would not have benefited as much. Furthermore, demographics may also play a role in this finding since this study was done in a tertiary government hospital which serves patients of the lower socioeconomic ladder. Review of charts revealed frequent reference to financial constraints as a cause of treatment delay, and may also be contributory to the lengthy interval between primary and revision surgeries (eosinophilic group 9 years; non-eosinophilic 
group mean 18.33 years, range 1-37), however, a causal relationship cannot be determined in this paper.

Despite the controversy in the role of allergy in CRSWNP, this study has found that the eosinophilic group demonstrated a higher prevalence of asthma and atopy. Of the total study population, all patients with asthma and most patients with other forms of atopy $(68.18 \%)$ were subsequently classified under the eosinophilic endotype. This observation is to be expected having set the cut-off value based on positivity to EG2 immunohistochemical staining as this is also a clinically useful indicator for asthma. ${ }^{21} \mathrm{~A}$ significant limitation of this study is that the diagnosis of bronchial asthma and other forms of atopy was established clinically, as objective tests such as spirometry with bronchodilator challenge and specific lgE testing (e.g., skin prick testing, serum specific lgE testing) would have been preferred but are unavailable in our institution.

The listed conditions in the exclusion criteria were ruled out clinically through history, physical examination as well as the routine pre-operative diagnostics (paranasal sinus CT scan, CBC, coagulation studies, chest $\mathrm{x}$-ray, etc.) wherein symptoms, medical history or objective parameters that would increase suspicion of the listed criteria would undergo further investigation. In this study however, all patients had normal blood tests with no signs of immunodeficiency or coagulopathies, none of the listed conditions on history taking, no CT findings of prior craniofacial trauma or invasive fungal disease, unremarkable chest $\mathrm{x}$-ray with no situs inversus, no endoscopic findings of septal perforation or fungus ball as well as no histopathologic findings of hyphae within the tissue specimens. In this population, there was no note of a patient with Aspirin-Exacerbated Respiratory Disease (AERD) however one patient presented with asthma and allergy to non-aspirin NSAIDs, specifically ibuprofen and mefenamic acid. Upon review of the patient's chart, AERD was not listed as a co-morbidity, history of previous intake of aspirin was not elicited, nor oral aspirin provocation test performed. Futhermore, this patient's eosinophil count on histopathology was the highest of the population (215/hpf on the left, 135/hpf on the right). AERD is a difficult diagnosis to establish when relying on patient history alone. The prevalence of AERD in patients with or without asthma and CRSwNP was $23 \%$ upon evaluation with oral aspirin provocation test. ${ }^{5}$ However, since this is a retrospective review, the researchers cannot ascertain this diagnosis - another limitation in this study and possibly an avenue of further research.

Quality of Life (QOL) among patients with eosinophilic CRSwNP has been shown to be worse than among patients with non-eosinophilic CRSwNP.22 This can be observed in our study population where patients with the eosinophilic endotype had higher pre-operative SNOT-
22 scores (median 50.5), while the group with the non-eosinophilic endotype had lower scores (median 38). The results for pre-operative scores were presented using median as a measure of central tendency since there were extreme outliers noted in the data collected of the non-eosinophilic group which would skew the results and would not have been representative of each subtype. In this study, the Sinonasal Outcome Test 22 (SNOT-22) was performed in both English and Filipino between 2017-2019 since the validated Filipino version ${ }^{23}$ was only published in 2017. Prior to that (2015-2017), the SNOT-22 was only administered in English. Post-operative SNOT-22 scores were not included in this study, also another limitation.

While this study only looked at tissue eosinophilia to determine endotype, other measures may also be employed in future studies. The use of blood eosinophil count could be a good marker for mucosal eosinophilia in nasal polyps ${ }^{24}$ however local data is lacking and could be a useful avenue for further research. Interestingly, there are studies that show that peripheral eosinophilia significantly correlated with eosinophil infiltration in nasal polyps. ${ }^{16}$ Other measures to determine endotypes of CRSwNP could include the determination of severity using $\mathrm{CT}$ and endoscopy scores as well as rates of disease recurrence.

This study has determined a prevalence of $54.55 \%$ favoring the eosinophilic endotype, as opposed to Western countries (78-88\% eosinophilic $)^{7.8}$ and in contrast to our East Asian and South-east Asian neighbors, who have a predominantly non-eosinophilic endotype (53.6-90.47\%).9-12 Determination of endotype of patients with chronic rhinosinusitis have promising uses in the prognostication of these patients which further have implications in post-operative management. By knowing the endotype, the clinician will be able to individualize treatment. Once a patient has been diagnosed to have CRSwNP and the eosinophilic endotype has been determined, the clinician can then proceed with a more aggressive management of these patients in terms of frequency of follow-up, medication prescribed, screening for recurrent disease and patient education and counseling. Without knowing the endotype and with the consideration of the prevalence of this study, we may miss out on prescribing longterm low dose macrolides which is appropriate for the non-eosinophilic endotype. 


\section{ACKNOWLEDGEMENTS}

We would like to thank our department research head, Dr. Giancarla Ambrocio, and department chair, Dr. Samantha Castañeda, for their invaluable advice and assistance in keeping our progress on schedule. Our special thanks are extended to the staff of the Rizal Medical Center Hospital Information Management Department for their assistance in retrieving charts and histopathology results for this study.

\section{REFERENCES}

1. Kern R, Liddy W. Pathogenesis of Chronic Rhinosinusitis. In Flint PW, Haughey B, Lund V, Niparko J, Robbins K, Regan Thomas J et al., editors. Cummings Otolaryngology Head \& Neck Surgery. Philadelphia: Elsevier; 2014 p.714.

2. Jarvis D, Newson R, Lotvall J, Hastan D, Tomassen P, Keil T, et al. Asthma in adults and its association with chronic rhinosinusitis: The GA2LEN survey in Europe. Allergy. 2012 Jan;67(1):918. DOI: 10.1111/j.1398-9995.2011.02709.x; PubMed PMID: 22050239.

3. Hirsch AG, Stewart WF, Sundaresan AS, Young AJ, Kennedy TL, Greene JS et al Nasal and Sinus Symptoms and Chronic Rhinosinusitis in a Population-Based Sample. Allergy. 2017 Feb;72(2):274-281. DOI: 10.1111/all.13042; PubMed PMID: 27590749; PubMed Central PMCID: PMC5497579.

4. Zhang $Y$, Gevaert E, Lou H, Wang $X$, Zhang L, Bachert $C$, et al. Chronic rhinosinusitis in Asia. J Allergy Clin Immunol. 2017 Nov;140(5):1230-1239. DOI: 10.1016/j.jaci.2017.09.009; PubMed PMID: 28987810.

5. Chaaban MR, Walsh EM, Woodworth BA. Epidemiology and differential diagnosis of nasal polyps. Am J Rhinol Allergy. 2013 Nov-Dec;27(6):473-8. DOI: 10.2500/ajra.2013.27.3981; PubMed PMID: 24274222; PubMed Central PMCID: PMC3899526.

6. Koennecke M, Klimek L, Mullol J, Gevaert P, Wollenberg B. Subtyping of polyposis nasi: phenotypes, endotypes and comorbidities. Allergo J Int. 2018;27(2):56-65. DOI: 10.1007/s40629017-0048-5; PubMed PMID: 29564208; PubMed Central PMCID: PMC5842507.

7. Jankowski R, Bouchoua F, Coffinet L, Vignaud JM. Clinical factors influencing the eosinophil infiltration of nasal polyps. Rhinology 2002 Dec; 40(4), 173-178; PubMed PMID: 12526243

8. Vlaminck S, Vauterin T, Hellings PW, Jorissen M, Acke F, Van Cauwenberge P, et al. The importance of local eosinophilia in the surgical outcome of chronic rhinosinusitis: a 3-year prospective observational study. Am J Rhinol Allergy. 2014 May-Jun;28(3):260-4. DOI: 10.2500/ ajra.2014.28.4024; PubMed PMID: 24980239

9. Indrawati LPL. Expressions of Eosinophil in Chronic Rhinosinusitis Patients with Nasal Polyp. Otolaryngology Online Journal June 2018 [cited 2020 Aug.20];8(2) Available from: http://www. alliedacademies.org/articles/expressions-of-eosinophil-in-chronic-rhinosinusitispatients-withnasal-polyp-10389.html.

10. Jareoncharsi P, Bunnag C, Muangsomboon S, Tunsuriyawong P, Assanasane P. Clinical and Histopathological Classification of Nasal Polyps in Thais. Siriraj Med J Nov 2002. [cited 2020 Aug.20];54(11):689-97. Available from: https://he02.tci-thaijo.org/index.php/sirirajmedj/ article/view/245323.

11. Kim JW, Hong SL, Kim YK, Lee CH, Min YG, Rhee CS. Histological and immunological features of non-eosinophilic nasal polyps. Otolaryngol Head Neck Surg. 2007 Dec;137(6):925-30. DOl: 10.1016/j.otohns.2007.07.036; PubMed PMID: 18036422.
12. Cao PP, Li HB, Wang BF, Wang SB, You XJ, Cui YH, et al. Distinct immunopathologic characteristics of various types of chronic rhinosinusitis in adult Chinese. J Allergy Clin Immunol. 2009 Sep;124(3):478-84, 484.e1-2. DOI: 10.1016/j.jaci.2009.05.017; PubMed PMID: 19541359.

13. Shah SA, Ishinaga $\mathrm{H}$, Takeuchi K. Pathogenesis of eosinophilic chronic rhinosinusitis. J Inflamm. 2016 Apr;13:11. DOI: 10.1186/s12950-016-0121-8; PubMed PMID: 27053925; PubMed Central PMCID: PMC4822241

14. Lund VJ, Mackay IS. Staging in rhinosinusitus. Rhinology. 1993 Dec;31(4):183-4. PubMed PMID: 8140385.

15. Hopkins C, Gillett S, Slack R, Lund VJ, Browne JP. Psychometric validity of the 22-item Sinonasal Outcome Test. Clin Otolaryngol. 2009 Oct;34(5):447-54. DOI: 10.1111/j.1749-4486.2009.01995.x; PubMed PMID: 19793277.

16. Kountakis SE, Arango P, Bradley D, Wade ZK, Borish L. Molecular and cellular staging for the severity of chronic rhinosinusitis. Laryngoscope. 2004 Nov;114(11):1895-905. DOI: 10.1097/01. mlg.0000147917.43615.c0; PubMed PMID: 15510011.

17. Javierto $A B$, Roldan RA, Gosingan A. The Prevalence of Eosinophilic and Non-Eosinophilic Nasal Polyp in Patients who Underwent Functional Endoscopic Sinus Surgery in Rizal Medical Center from Year 2008-2012. Unpublished observations.

18. Lou H, Zhang N, Bachert C, Zhang L. Highlights of eosinophilic chronic rhinosinusitis with nasal polyps in definition, prognosis, and advancement. Int Forum Allergy Rhinol. 2018 Nov;8(11):1218-1225. DOI: 10.1002/alr.22214; PubMed PMID: 30296011; PubMed Central PMCID: PMC6282610.

19. Nakayama T, Yoshikawa M, Asaka D, Okushi T, Matsuwaki Y, Otori N, et al. Mucosal eosinophilia and recurrence of nasal polyps-new classification of chronic rhinosinusitis. Rhinology. 2011 Oct;49(4):392-6. DOI: 10.4193/Rhino10.261; PubMed PMID: 21991563.

20. Matsuwaki Y, Ookushi T, Asaka D, Mori E, Nakajima T, Yoshida T, et al Chronic Rhinosinusitis: Risk Factors for the Recurrence of Chronic Rhinosinusitis Based on 5-Year Follow-Up after Endoscopic Sinus Surgery. Int Arch Allergy Immunol. 2008;146 (Suppl 1):77-81. DOI: 10.1159/000126066; PubMed PMID: 18504412.

21. Kamada Y, Kayaba H, Ito W, Ueki S, Kobayashi Y, Yamada Y, et al. EG2 expressed by eosinophils as a clinically useful indicator of asthma. Allergy Asthma Proc. 2008 Nov-Dec; 29(6):609-13. DOI: 10.2500/aap.2008.29.3171; PubMed PMID: 19173787.

22. Soler ZM, Sauer DA, Mace J, Smith TL. Relationship between Clinical Measures and Histopathologic Findings in Chronic Rhinosinusitis. Otolaryngol Head Neck Surg. 2009 Oct;141(4):454-61. DOI: 10.1016/j.otohns.2009.06.085; PubMed PMID: 19786212; PubMed Central PMCID: PMC2766519.

23. Maningding CAC, Roldan RA. Reliability and Validity of the Filipino Sino-Nasal Outcome Test (SNOT) 22. Philipp J Otolaryngol Head Neck Surg. 2018 Jan-Jun; 33(1):17-20. DOI: 10.32412/ pjohns.v33i1.51.

24. Sun C, Ouyang H, Luo R. Distinct characteristics of nasal polyps with and without eosinophilia. Braz J Otorhinolaryngol. 2017 Jan-Feb;83(1):66-72. DOI: 10.1016/j.bjorl.2016.01.012; PubMed PMID: 27166273. 